\title{
Research Paper: The Relationship Between Religious Attitudes and Death Anxiety in the Elderly People
}

\author{
Fatemeh Ghasemi ${ }^{1}$, Alireza Atarodi ${ }^{* *}$, Seyed Saeid Hosseini ${ }^{3}$ Q
}

1. Department of Social Sciences, School of Humanities, Islamic Azad University of Gonabad Branch, Gonabad University of Medical Sciences, Gonabad, Iran.

2. Paramedical College and Social Development \& Health Promotion Research Center, Gonabad University of Medical Sciences, Gonabad, Iran

3. Department of Social Sciences, School of Humanities, Gonabad Branch, Islamic Azad University, Gonabad, Iran.

$\begin{gathered}\text { Use vour device to scan } \\ \text { and read the artide online }\end{gathered}$
Pteople. Journal of Research \& Health. 2020; 10(3):135-142. http://dx.doi.org/10.32598/JRH.10.3.773.11
dof": http://dx.doi.org/10.32598/JRH.10.3.773.11

() 03

Article info:

Received: 10 Jan 2020

Accepted: 05 Apr 2020

Publish: 01 May 2020

\section{Keywords:}

Religion, Attitude to death, Death anxiety, Elderly people, Ageing

\section{A B S TRACT}

Background: Late adulthood, as a sensitive life period of humans, requires unique attention. Elderly people are faced with challenging conditions, including death anxiety. This research aimed to investigate the relationship between religious attitudes and death anxiety in the elderly population of Gonabad City, South Khorasan Province, Iran.

Methods: It was a cross-sectional and correlational study. The study sample included 200 adults older than 60 years. The sample is collected from the adult population of Gonabad City using the random sampling method. The obtained data were analyzed with G Power 3.0.10 software. The religious attitudes questionnaire of Khodayarifard et al. was used to evaluate four religiosity dimensions: religious convictions, affections, behaviors, and social pretensions. A high score in each subscale implies greater religiosity tendencies. The Templer questionnaire was also used to assess the anxiety of death. This questionnaire includes the fear of death; the fear of pain and disease; the thoughts of death, passing time, and shortening life; and the fear of the future. The data were analyzed with the Mann-Whitney, Kruskal-Wallis, and Spearman tests.

Results: The religious attitudes were inversely correlated with death anxiety. This implies that the anxiety has decreased as religious attitudes have increased. This research showed a relationship between death anxiety and the population variables (education level, the source of revenue, etc.) This study also indicated a connection between religious attitudes and population variables (marital status, educational level, the source of revenue, lifestyle, and financial status).

Conclusion: According to the present findings, a better religious approach could improve mental health and decrease death anxiety among elderly people.

\footnotetext{
* Corresponding Author:

Alireza Atarodi

Address: Paramedical College and Social Development \& Health Promotion Research Center, Gonabad University of Medical Sciences, Gonabad, Iran

Phone: +98 (915) 5331034

E-mail: aratarodi1387@yahoo.com
} 


\section{Introduction}

ne of the contemporary emerging fields of psychology is aging psychology called cognitive geriatric. The growth of the elderly population has drawn the specialists' attention to the fundamental requirements of this population, including mental and psychological well-be-

ing. Aging is one of our era phenomenon that we can confront with it easily [1].

Iran, as a developing nation with a rapid population rise in 1981s, will face an excess of older people's expectations in the future, and its $8 \%$ elderly population will rise to $22 \%$ in 2046 . This demographic crisis creates a tsunami of elderly people in Iran. According to the recent reports of Iran's Statistics Center, the number of our elderly population was 7450000 in 2017 . So around $30 \%$ of our population will be old in 2050. Seventy percent of the population is now active (ie, people between the ages of 15 and 60). Since 2006, when a pop-up window opened in our country, the young population has grown and the number of elderly people also increased [2].

The reality of death has been marginalized in contemporary society, but this inevitable fact, as a pattern of thinking, must be resolved in communities, particularly in the elderly population. Death is related to the lack of human or the end of life; it creates a gap in several social interactions, including private, financial, political, and ethical interactions that influence the society [3].

Religion is regarded as a set of do's and don'ts beliefs, as well as the proprietary and generalized values of the most effective psychological support that can provide the meanings of life at the moment of life. On the other hand, religion, as a mediator, affects the thinking process and evaluates the daily events of a person's life. Staying away from the real religious convictions paves the way for people to experience inner and psychological disputes, the emotion of emptiness and desperation, the frustration of deprivations, afflictions, and psychological pressures [1].

Death as a significant life event has a complicated idea and a lot of pain and suffering can accompany it. Anxiety about death is more prevalent in late adulthood. Because this period of life is full of all the types of deficiencies and disabilities. Studies have shown that elderly people are more prone to anxiety owing to decreased self-esteem, low activity and motion, the loss of friends and families, decreased physical and economic autonomy, and chronic diseases. Thus, the most prevalent anxiety may be the death anxiety in this period of life [4].

Death anxiety is an emotional sense of not getting a pleasant life. An individual who suffers from death anxiety does not enjoy life and this anxiety makes him feel unimportant. One way of reducing anxiety and fear of death is to switch to religion and social practices; adverse attitudes toward religion have been shown to increase the fear of death [4].

The death anxiety in aging period is a significant and efficient variable. Because of the reasons, including disability, the loss of their spouse or child, retirement, etc., elderly people are mostly concerned about their persistence. This concern imposes a great deal of burden on themselves, their families, society, and the health communities. It also causes social isolation, mental imbalance, disease and vulnerability, and inactivity. However, reducing the death anxiety positively affects the community, and motivates us to make our efforts to reduce it and to draw an effective conclusion from the aging phenomenon. Nearly all researchers agree that the degree of death anxiety, particularly the fear of death, is considerably lower in religious environments and societies with more religious convictions than in non-religious communities. Religious individuals find life more meaningful, they have a greater life expectancy, and then, feel less anxiety about death [5].

Societies that practice more religion have less anxiety about death. Also, people with intrinsic motivation have less anxiety about death. The severity of death anxiety is also associated with greater faith in the post-death globe. Death anxiety is also associated with depression, widespread anxiety, and suicidal thoughts, all leading to the reduced function of individuals [6].

The fast rise of the elderly population seems to be a considerable problem. According to the recent reports of Iran's Statistics Center, the number of elderly people in our nation was 7450000 in 2017. This number accounts for $9.3 \%$ of the country's total population, and will represent $30 \%$ of our population in 2050 . According to a study by the Young Journalists Club of Mashhad, Gonabad is the second aging city in the nation. The elderly people should be prevented from isolation and their experiences must be used for the development of this city. Also, we need to safeguard the elderly people as a factor of family solidarity and prevent them from desperation. Therefore, the problems of the elderly should be taken into account, particularly in the cultural and social fields [7]. 
Religion develops defensive protection in people against environmental stressors. Also, religious convictions lead to a broad variety of beneficial psychological impacts on individuals. According to Allameh Tabatabai, believers have based their affairs on the teachings of honesty and decisive opinions and trusted to a strong and eternal foundation. They act on divine commands and believe that nothing is belonging to them; thus, they do not fear the loss of anything. Allameh considered the unbelievers as an unaccompanied people who do not receive treatment, and their ideas and dreams make them seriously anxious [8].

According to the results of previous studies, the rate of death anxiety is high among non-elderly individuals. Masoudzadeh et al. reported that among the public hospital staff of Sari City with the age range of 20 to 53 years, $42.2 \%$ and $57.8 \%$ of people have low and high death anxiety, respectively [9].

Another research indicated that the death, fear, and excitement are inevitable phenomena, particularly in older people, and since no one has witnessed or endured death, thinking about it creates death anxiety [10]. Furthermore, the treatment of distinct religions with death anxiety and the presence of anxiety in elderly people imply that the anxiety and fear of death are prevalent in all societies and distinct groups and religions. Empirical surveys have shown that fear of death is more prominent in elderly people, and death anxiety invades them more [11].

Evidence indicates that religion can help people to relieve the death anxiety. Given that the tendency to religion, as a human need, rises during adulthood and the elderly people are more religiously matured in this sensitive period, this study aimed to determine the connection between religious attitudes (including religious beliefs, religious behavior, religious affections, and social affairs) and death anxiety among the elderly population of Gonabad City.

\section{Methods}

\section{Study Participants}

This research was a descriptive-correlational study with a cross-sectional design. This research aimed to investigate the connection between religious attitudes and death anxiety in the elderly population of Gonabad City, in 2018. The study population included 6264 elderly individuals (age range: 60-95 years) who were residing in Gonabad City.
The multi-stage sampling technique was used to select the samples. Initially, three centers were randomly selected among the health center communities of Gonabad City. Then, a randomized cytometric technique was used to select the samples from each center. Each center prepared a distinct list of the elderly males and females aged 60 years and above. Based on the number of elderly people in each center, the first sampling interval was calculated among the elderly population. Then, a random number of 1 was selected for sampling spacing and continued to reach the required sample size.

A total of 200 elderly people who met the study criteria were selected as the study sample. The number of samples selected at centers 1, 2, and 3 were 98, 46, and 56, respectively. After explaining the research goals and obtaining informed consent, the elderly people completed the self-report questionnaires; those, who were unable to complete the questionnaire, answered the questionnaires with the assistance of the researcher. The inclusion criteria were as follows: the readiness to engage in the research, the age range of 60 to 95 years, the lack of mental or physical disorder, the non-use of antidepressants and sedatives, and the ability of collaboration. The exclusion criteria also included being unready for cooperation and being unable to fully answer the questions.

\section{Study Measures}

\section{Demographic information}

An anonymous questionnaire was used to obtain the demographic information: age, gender, marital status, educational level (non-literate, Quranic reading skills, primary school, secondary school, high school diploma, and greater educational level), employment status (housewife, employed, and retired), financial status (excellent, moderate, and bad), revenue source (no income, pensions, and relief commission), current diseases (healthy, cardiovascular, pulmonary, high blood pressure, diabetes, digestive system, kidney and urinary tract, arthritis, psychiatry, eye disease, hearing problems, etc.) coexistence status (single, spouse, children, spouse and kids, relatives and friends, etc.) and the number of offspring.

\section{Templer death anxiety inventory}

This questionnaire includes 15 items and 5 dimensions. Each correct and incorrect option is scored by 1 and 0 , respectively. The questionnaire dimensions include the fear of death (items 1, 12, and 14), the fear of pain and disease (items 2, 4, 6, and 13), the thoughts of death (items 5, 9, and 11), transient time and short life 
(items 8 and 15). We mixed the results for each item to obtain a complete score for that level.

This questionnaire evaluates the participant attitudes towards death and is scored from 0 (no death anxiety) to 15 (high death anxiety). The questionnaire includes cutoff points for the low (0-6), moderate (6 and 7), and high (7-15) levels of death anxiety. Tavakoli et al. studied the reliability and validity of the Templer death anxiety inventory; the validity was reported 0.87 using a test-retest technique. The reliability and the content was also approved by the relevant specialists in the field, as well [12].

\section{Khodayarifard religious attitude questionnaire}

The questionnaire contains 40 items and 4 subscales that includes religious views (items 1, 4, 7, 11, 14, 17, $21,24,27,31,34$, and 37), religious affections (items $3,6,9,13,16,19,23,26,29,33,36$, and 39), religious behaviors (items 2, 5, 8, 12, 15, 18, 22, 25, 28, 32, 35, and 38 ), and social pretensions (items 10, 20, 30, and 40). This questionnaire measures religious behavior in relation to religious convictions.

The questionnaire is scored based on a 6-point Likerttype scale from 0 (never) to 5 (always); thus, the scores of 40 and 200 show the absence of a religious approach and a very high religious attitude, respectively. The median number of 120 was regarded as the cut-off point that dif-

Table 1. Demographic information of the study samples

\begin{tabular}{|c|c|c|}
\hline Demographic Information & Value Units & No. (\%) \\
\hline \multirow{4}{*}{ Age range (y) } & $60-69$ & $107(53.5)$ \\
\hline & 70-79 & $66(33)$ \\
\hline & $80-89$ & $22(11)$ \\
\hline & $90-95$ & $5(2.5)$ \\
\hline \multirow{2}{*}{ Sex } & Men & $94(47)$ \\
\hline & Women & $106(53)$ \\
\hline \multirow{4}{*}{ Marital status } & Married & $155(77.5)$ \\
\hline & Single & $4(2)$ \\
\hline & Widow & $39(19.5)$ \\
\hline & Divorced & $2(1)$ \\
\hline \multirow{3}{*}{ Education level } & Illiterate & $36(18)$ \\
\hline & Undergraduate & $142(71)$ \\
\hline & Graduate & $22(11)$ \\
\hline \multirow{3}{*}{ Economic status } & Well & $32(16)$ \\
\hline & Moderate & $135(67)$ \\
\hline & Poor & $33(17)$ \\
\hline \multirow{6}{*}{ Life status (living with others) } & Alone & $17(8.5)$ \\
\hline & Wife & $89(44.5)$ \\
\hline & Children & $24(12)$ \\
\hline & Wife \& children & $64(32)$ \\
\hline & Families & $5(2.5)$ \\
\hline & Others & $1(0.5)$ \\
\hline \multirow{3}{*}{ Number of children } & No child & $6(3)$ \\
\hline & Up to 7 & $169(84.5)$ \\
\hline & Over 7 children & $25(12.5)$ \\
\hline
\end{tabular}


ferentiates between the high religious attitudes (120-200) and the low religious attitude (120 or less). A high score in each subscale implies greater religiosity tendencies.

Greater overall score on this scale indicates the greater values of the religious belief of the study sample. Khodayarifard et al. reported 0.96 and 0.94 of reliability and validity indices, respectively. Reliability Coefficient by retest method was calculated 0.91 , and by half-splitting method of Spearman-Brown was calculated 0.82 and also by Gutman method it was 0.80 for whole the questionnaire. The scales of death anxiety and religious attitudes have bipolar states that are characterized as elevated and low [13].

Inferential statistics were also used to evaluate the study outcomes. Using statistical methods, the information was presented using specific techniques, tabulation, and classification. The questionnaire information was evaluated in SPSS v. 22. The findings were provided in the form of graphs and tables using Excel software. The Kolmogorov-Smirnov and Shapiro-Wilk tests evaluated the normality of all quantitative factors. Some variables, including religious attitude and the scores of anxiety, did not meet the normality assumption. Therefore, the Kruskal-Wallis test, nonparametric Mann-Whitney, and the correlation coefficient of Spearman were used for the analysis of these variables at the significant level of 0.05 .

One of the ethical considerations of the study was to give permission to the elderly people and to assure them about the confidentiality of data. After the evaluation of the research data, the findings are presented in the Tables 1-4.

\section{Results}

Table 1 shows that the age of 107 participants (53.5\%) was between 60 and 69 years. In this research, the average age of 106 females (53\%) and 94 males (47\%) was 69.8 years $(\mathrm{SD}=7.8)$. In terms of marital status, 155 people $(77.5 \%)$ were married. The educational level of 142 people (71\%) was below the diploma. Eighty-one people $(40.5 \%)$ were housewives, and 135 participants $(67 \%)$ reported a moderate financial status. Pension benefits were used by 100 participants $(50 \%)$. In terms of present diseases, 100 people $(50 \%)$ had more than one illness. Eighty-nine people (44.5\%) lived with their husbands, and 169 participants $(84.5 \%)$ had up to 7 children.

According to Table 2, men and women do not significantly differ in the dimensions of death anxiety and religious attitudes $(\mathrm{P}>0.05)$. The Spearman correlation test showed a statistically significant correlation between the variables of religious attitude and death anxiety $(\mathrm{P}<0.05)$.

According to Table 3, there is a significant and inverse relationship between the dimensions of religious attitude and death anxiety. These results suggest that the amount of death anxiety can be lowered concerning religious orientation.

The results of the Kruskal-Wallis test for the variables of religious attitude and death anxiety indicated that the source of revenue and living status are significantly associated with the religious attitude variables. Also, the factors of death anxiety were associated with living status and the number of children. The tests showed that mari-

Table 2. The status of religious attitude and death anxiety in the study sample

\begin{tabular}{|c|c|c|c|}
\hline Variables & Sex & Mean $\pm S D$ & Mann-Whitney U \\
\hline \multirow{2}{*}{ Religious attitude } & Women & $18.66 \pm 62.50$ & \multirow{2}{*}{0.94} \\
\hline & Men & $20.66 \pm 54.91$ & \\
\hline \multirow{2}{*}{ Death anxiety } & Women & $3.8 \pm 34.53$ & \multirow{2}{*}{0.75} \\
\hline & Mean & $2.8 \pm 97.64$ & \\
\hline
\end{tabular}

WRA

Table 3. Correlation Matrix of Religious Beliefs and Death Anxiety

\begin{tabular}{cccc}
\hline & & \multicolumn{2}{c}{ Death Anxiety } \\
\cline { 2 - 4 } Correlation Test & No. & Correlation Coefficient & P \\
\hline Religious belief & 200 & $187.0-$ & 00.0 \\
Religious affections & 200 & $141.0-$ & 0.04 \\
Religious behaviors & 200 & $213.0-$ & 02.0 \\
Social pretensions & 200 & $151.0-$ & 03.0 \\
\hline
\end{tabular}


Table 4. The Relationship of demographic information, religious attitude, and death anxiety

\begin{tabular}{ccc}
\hline Variables & $\begin{array}{c}\text { The Kruskal-Wallis Test for the Reli- } \\
\text { gious Attitude Variables }\end{array}$ & $\begin{array}{c}\text { The Kruskal-Wallis Test for Death } \\
\text { Anxiety Variables }\end{array}$ \\
\hline Married & 09.0 & 0.66 \\
\hline Education level & 11.0 & 0.18 \\
\hline Economic source & $01^{*} .0$ & 0.15 \\
\hline Economic status & 26.0 & 0.84 \\
\hline Living with others & $02 * .0$ & $0.33^{*}$ \\
\hline No. of children & 69.0 & $0.02 *$ \\
\hline * & &
\end{tabular}

tal status, educational level, and financial status were not related to studied variables.

\section{Discussion}

Generally, a significant and inverse correlation was observed between religious attitudes and death anxiety, in the present research. This result implies that anxiety reduces as religious attitudes rise. This finding is consistent with the results of several previous studies. Research findings from this stage of the hypothesis are compatible with the outcomes of Abdul Khaleq [13], Heidari [14], Wen [12], Zareipour [11], Mehrinejad [6], and Wafaei [10]. Describing the study outcomes, it can be stated that death anxiety reduces in people with higher religious convictions because religious people find life more meaningful, their life expectancy is higher, and death anxiety, particularly fear of death, is lower in them. Given that Iran's society is Islamic and religious, this finding may seem natural. The results of religious behaviors can be seen in decreasing anxiety and stress, and growing hope for the future. Worship can turn hope, forgiveness, and love to the favorable emotional experiences. Naturally, individuals with a religious approach tend to regard events more favorable and as a divine fate, resulting in a more balanced fear of death. In this research, there was a significant and inverse relationship between the aspects of religious attitude (including religious convictions, religious behavior, religious affections, and social pretensions) and death anxiety.

The study of demographic factors and religious attitudes showed that religious attitudes are significantly associated with the source of revenue and living status, but religious attitudes are not associated with age, gender, marital status, educational level, employment status, financial status, and the number of children. The study results of Jahangiri and Mehri Nejad [6], for example, confirm the relation between age and religious attitudes. However, these findings are inconsistent with the outcomes of Zareipour [11] and Rahmani Firoozjah [15]; this fact implies that the religious attitudes of younger individuals are considerably lower than that of the older individuals, or the religious attitudes become deeper as the age rises.

The adolescence period can be an effective factor, because of the identity crisis, the unfamiliarity with religious affairs, and laziness in religious activities. Another reason for this difference may be the decrease in people's religious tendencies to learn religious materials owing to variables, such as economic stress, movies, and TV series in the post-war years.

The findings of this study show no significant gender difference in death anxiety and religious attitudes. These results are consistent with the findings of $\mathrm{Na}$ 'imi et al. [16], Gharraee [17], Meheri Nejad [6], Aflakseir [18], and Abdul Khaleq [13]. However, the findings of some studies, such as Peiman [19], Ghufran [20], and Cicirelli [21] are inconsistent with our findings.

The study of demographic factors and death anxiety showed a significant relationship between death anxiety, family status, and the number of children, in the study sample. However, death anxiety is not associated with age, gender, marital status, education, employment status, source of revenue, and financial status, in the study sample.

The findings indicated a significant beneficial connection between life status and death anxiety, in the elderly population. This fact implies that family members can be a source of support and hope for elderly individuals, and can also decrease the stress and death anxiety in elderly people. The findings also represented a significant negative correlation between the number of children and death 
anxiety. Azaiza [22] showed that having a family and kids plays a major role in decreasing the anxiety of death.

Elderly people who are living with their families and children are more comfortable, confident, and pleasant, regardless of the weakness and suffering of the old age, because they have regarded others in the family. Together, with their family and loved ones, their life expectancy rises, and they tend to enhance their future, even in a short period. At the same time, their concern either financially, physically, or in terms of self-esteem is reduced. Interacting and consulting with them enhances their willingness to engage, and their involvement in life affairs makes them stronger. This approach reduces concerns, improves life satisfaction, increases life expectancy, and leads to lower death anxiety in elderly people.

\section{Conclusion}

The findings demonstrated that religious attitudes had a beneficial and substantial impact on the decrease of anxiety in the elderly individuals of Gonabad City. Religious attitudes were inversely related to the levels of anxiety in elderly individuals. However, the relation of demographic variables with attitudes and anxiety seems different compared with the outcomes of the other studies. This difference can result from the diverse type and the number of studied samples and the research populations. The elderly people are regarded as a community resource because of their life experiences.

Therefore, the physical and mental needs of these individuals should be considered in society. An old person has to inevitably tolerate many distresses, such as the shift in work status, the loss of physical fitness and wellbeing, and the death of his/her spouse, friends, children, family members, and colleagues. Elderly people are also influenced by modifications that can lead to depression and anxiety. Positive religious convictions like patience, trust, certainty, tolerance, and life satisfaction can make their lives meaningful.

Life and death make individuals believe more meaningfully and deeply and trigger hope, control, and efficacy. In the current research, There was a significant inverse correlation between religious attitudes and death anxiety, among elderly people. That is, as religious attitudes grow the death anxiety declines, because as individuals become older they conclude that the trust and the peace of life are associated with God, and they pursue the only non-fatal nature.
Overall, this research discovered that religious attitudes had a huge impact on the decrease of death anxiety in elderly people. Therefore, more attention is required to teach religion theoretically and practically and to create profound beliefs in elderly individuals. Based on religious attitudes, the results of this study can be used to plan to reduce death anxiety.

\section{Ethical Considerations}

\section{Compliance with ethical guidelines}

The research was approved by Vice Chancellor for Research of Gonabad Islamic Azad University (Code: 09.20.2.7569) on January 15, 2020.

\section{Funding}

This research did not receive any specific grant from funding agencies in the public, commercial, or non-profit sectors.

\section{Authors' contributions}

All authors contributed in designing, running, and writing all parts of the research.

\section{Conflict of interest}

The authors declared no conflicts of interest.

\section{Acknowledgments}

The authors would like to thank all the research managers of the Islamic Azad University of Gonabad, the health centers of the Gonabad University of Medical Sciences and the related officials, all involved staff, and the participants of this study.

\section{References}

[1] Imanzadeh A, Hamrahzdeh M. Identification of facilitators and deterrents of the Quality of Life in elderly women and men: A phenomenological research. Salmand: Iran J Ageing. 2018; 12(4):430-45. http://salmandj.uswr.ac.ir/article1-1248-fa.html

[2] Amini Rastaee Z. [Religious attitude and life satisfaction in elderly women (Persian)]. Paper presented at: The First National Conference on Islam and Mental Health. 22-23 April 2015; Bandar Abbas, Iran. https://www.civilica.com/PaperCIMH01-CIMH01_032.html 
[3] Talebi M. [The phenomenology of death (study of the meaning of death) (Persian)] [MA. thesis] Mashhad: Ferdowsi Univ Mashhad; 2011. https:/ / www.virascience.com/thesis/519367/

[4] Valaei N, Zalipoor S. [The effectiveness of therapeutic meaning on anxiety of death elderly (Persian)]. J Aging Psychol. 2015; 1(1):49-55. http://jap.razi.ac.ir/article_289.html

[5] Ali Akbari Dehkordi M, Oraki M, Barghi Irani Z. [Relation betweereligious orientation with anxiety about death, and alienation in aged peoples (seniors) in Tehran (Persian)]. Soc Psychol Res. 2011; 1(2):140-59. https://www.sid.ir/fa/journal/ViewPaper.aspx?id=163637

[6] Mehri Nejad SA, Ramezan Saatchi L, Paydar S. [Death anxiety and its relationship with social support and adherence to religion in the elderly (Persian)]. Salmand: Iran J Aging. 2017; 11(4):494-503. [DOI:10.21859/sija-1104494]

[7] Kakaboraee K, Moazinejad M. [The relationship between finding meaning in life and demographic characteristics with death anxiety in the elderly (Persian)]. J Aging Psychol. 2016; 2(1):37-47. https://jap.razi.ac.ir/article_500_en.html

[8] Ghaseminia P, Ranjbar Ghadim NS. [Psychology of death (Persian)]. J N Adv Behav Sci. 2017; 2(9):50-63. http://ijndibs. com/article-1-80-fa.html

[9] Youth Journalists Club. Gonabad is the second oldest city in Iran (Persian)] [Internet]. 2017 [Updated 2017 September 6] Available from: https://www.yjc.ir/00Q9VK

[10] Vafaii Z, AskarizadehQ, Rahmati A. [Therelationship of impulsive sensation-seeking, humor and religious attitude with death anxiety (Persian)]. Ravanshenasi Va Din. 2012; 4(3):4968. https://www.magiran.com/paper/961204?lang=en

[11] Zareipour MA, Sadeghi R, Abdolkarimi M, Ghasemi Afshar N, Jadgal MS. [The relationship between religious attitudes and psychological symptoms in pregnant women referring to Urima health centers in 1395 (Persian)]. J Res Relig Health. 2019; 4(5):45-56. [DOI:10.22037/jrrh.v4i5.16758]

[12] Wen, Y-H. Religiosity and death anxiety. The Journal of Human Resource and Adult Learning. 2010; 6(2):31-7. http:/ / www.hraljournal.com/Page/4\%20Ya-Hui\%20Wen.pdf

[13] Abdel- Khalek A, Lester D. Religiosity and death anxiety: No Association in Kuwait. Psychol Reports. 2009; 104(3):7702. [DOI:10.2466/PR0.104.3.770-772] [PMID]

[14] Heydari E, Khalili Sharafeh F, Khodapanahi MK. [Relationship between religious orientation, death anxiety \& sensation seeking (Persian)]. J Psychol. 2009; 13(3):325-41. https:/ / iranjournals.nlai.ir/2467/article_588605.html

[15] Rahmani Firoozjah A, Niazi Orimi F. [Sociological evaluation of the people's attitudes towards the afterlife (case study: The population with the age of over 20 years old in the city of Babol) (Persian)]. J Islam Soc Sci. 2015; 6(12):186-49. http:// soci.rihu.ac.ir/article_1021.html

[16] Naeimi E, Kazemi Z, Dehghan K. [The relationship between the religious orientation and irrational beliefs in the elderly of Kahrizak sanitarium (Persian)]. Clin Psychol Stud. 2016; 6(23):180-99. [DOI:10.22054/JCPS.2016.4564]

[17] Gharraee B, Ahmadvand A, Aakbari A, Zenozian S. [Relationship between mental health and intrinsic-extrinsic religion in Kashan (Persian)]. Tabriz Univ J Manag Syst. 2008, 3(10):61-84. https://journals.tabrizu.ac.ir/article_4338.htm
[18] Aflakseir A. [Reasons for death fear and religiosity and anxiety among students of university of Shiraz (Persian)] Tabriz Univ J Manag Syst. 2014; 9(35):19-32. https:/ / journals. tabrizu.ac.ir/article_3997.html

[19] Peiman A. [Investigating the relationship between general health, religious attitude and demographic characteristics with death anxiety in the elderly in Tehran (Persian)]. [MA thesis] Tehran: Allameh Tabatabaee University. https:// www.civilica.com/Paper-TSCONF01-TSCONF01_017.html

[20] Ghufran M, Sameena Ansari. Impact of widowhood on Religiosity and death anxiety among senior citizens. J Indian Acad Appl Psychol. 2008; 34(1):175-80. http://medind.nic. in/jak/t08/i1/jakt08i1p175.pdf

[21] Cicirelli VG. Fear of death in older adults, prediction from terror management theory. J Gerontol. 2002; 57(4):358-66 [DOI:10.1093/geronb/57.4.P358] [PMID]

[22] Azaiza F, Ron P. Death and dying anxiety among elderly Arab Muslims in Israel. J Death Stud. 2010; 34(4):351-64. [DOI:10.1080/07481181003613941] [PMID] 